\title{
Factors Affecting the Treatment Adherence in Dyspepsia Patients
}

\author{
İzzet Fidancı ${ }^{1}$, Şükrü Ümit Eren ${ }^{2}$ \\ ${ }^{1}$ Atakum Community Health Center, Samsun, Turkey \\ ${ }^{2}$ Kızılırmak State Hospital, Çankırı, Turkey
}

Email address:

izzetfidanci@gmail.com (İ. Fidancı)

\section{To cite this article:}

İzzet Fidanc1, Şükrü Ümit Eren. Factors Affecting the Treatment Adherence in Dyspepsia Patients. Journal of Family Medicine and Health Care. Vol. 1, No. 1, 2015, pp. 8-10. doi: 10.11648/j.jfmhc.20150101.13

\begin{abstract}
Dyspepsia is a common complaint seen in the community and patients applying to health institutions and its definition has changed in recent years. It has many reasons among which gastroesophageal reflux disease, peptic ulcer and functional dyspepsia are the most common. Prevalence numbers changing between 3\% and 40\% were reported in the studies made in Europe, North America and Oceanian countries. Just like the medicine use in all chronic diseases, there are factors affecting the treatment adherence of dyspepsia patients. The reasons for inadherence in dyspepsia treatment were studied in this compilation.
\end{abstract}

Keywords: Dyspepsia, Treatment Adherence

\section{Introduction}

Dyspepsia is a Greek origin word combined from dys meaning difficulty or bad and pepsis meaning ripening and digesting. The latest definition of dyspepsia is epigastric centred pain or discomfort which may generally be related or unrelated to eating or of recurrent or continuous character and it may have just started when the patient applied to a doctor or be present for months or even years $(1,2,3,4)$.

Dyspepsia is higher in males than females and the prevalence is low in elder people (5). In different societies it was found the dyspepsia prevalence changes between $25-50 \%$ $(3,4,5,6)$. If pathological causing dyspepsia can be detected in examinations on patients applying with dyspepsia complaint, this kind of dyspepsia are defined as functional dyspepsia if it is not found responsible for organic dyspepsia, a local or systematic disease (3). In a large-scale dyspepsia questionnaire made on 3543 cases in our country, it was determined that the average age was 38 and $30.8 \%$ of the cases had applied with a symptom. Also in the endoscopic examination of the cases with dyspeptic symptoms, gastritis in $32.6 \%$, duodenal ulcer in $23.4 \%$, gastric ulcer in $2 \%$ and normal findings in $41.8 \%$ were determined (7).

Cases which apply with dyspepsia for the first time and have no alarm symptoms should be examined psychiatrically and physically and medical history should be learned. Empirical acid suppression treatment should be started in patients younger than 55 years of age who have chronic symptoms but no alarm symptoms, if there is no response or the symptoms recur, $H$. pylori should be tested and eradication treatment should be made $(4,8,9)$. If symptoms continue after H. pylori eradication and in those with negative $\mathrm{H}$. pylori or were empirically treated, endoscopic examination is required. In cases over 45 years of old and have alarm symptom, in addition to gastrointestinal endoscopic examination, processes such as biochemical tests, ultrasonography and gastroduodenal manometry should be mandatory $(4,10,11)$. Alarm symptoms in dyspepsis are listed in Table 1.(4)

\section{Table 1. Alarm symptoms in dyspepsia.}

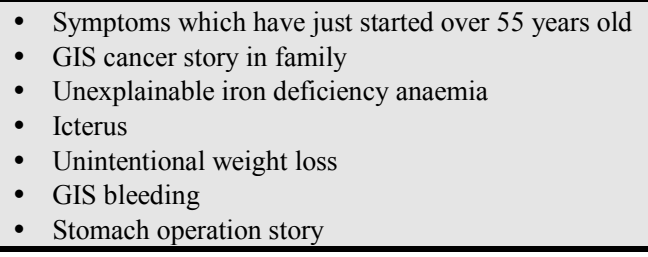

\subsection{Factors Affecting Treatment Adherence}

Treatment adherence can be defined under two titles and both should be present for a successful treatment:

a. Compliance: Adherence of patient to the appointments, medical advices, organizing living conditions to the disease and treatment,

b. Cooperation, adherence: It may be defined as patient 
taking the prescribed medicine with the required number and duration, going to the medical institution appointments without delay $(12,13,14)$. The aim should be stating patient and doctor demands, sharing responsibilities, making collaboration for treatment plan. Patient should know what, when and where to use and how to ask for help.

The patient who refused the treatment at the beginning should not be considered negatively. Missing only one appointment with a reasonable cause (such a trip abroad) should not be defined as inadherence $(15,16,17)$. In their study on treatment under direct observance, O'Boyle et al defined patients' not taking medicine more than seven successive days as treatment inadherence $(14,18)$. Patient medicine usage can be categorized in four groups:

1. Appropriate use: The patient takes medicine in the recommended way (adherent patient).

2. Incomplete use: Patient uses medicines less than the recommended amount (inadherent patient).

3. Over use: Patient uses medicines more than the recommended amount (inadherent patient).

4. Wrong use: Patient takes medicine in different times and more or less than the recommended amount (inadherent patient).

Although there is inadherence in the last three conditions, as patient taking medicine less than the recommended amount is considered inadherence, the others are classified as adherent by mistake. In the end they are all affective on the effects and side effects of the treatment $(14,19)$.

\subsection{Factors Affecting Patient Adherence}

It is impossible to guess which patient would be inadherent to the treatment. Treatment inadherence may be present in all kinds of diseases and patients in any socio-demographical group. As the importance of patient adherence is understood, investigation of the affecting factors accelerated. These can be grouped as reasons about the patient and/or disease and medicines (Table 2) $(14,20)$.

Table 2. Factors affecting the treatment adherence in dyspepsia patients.

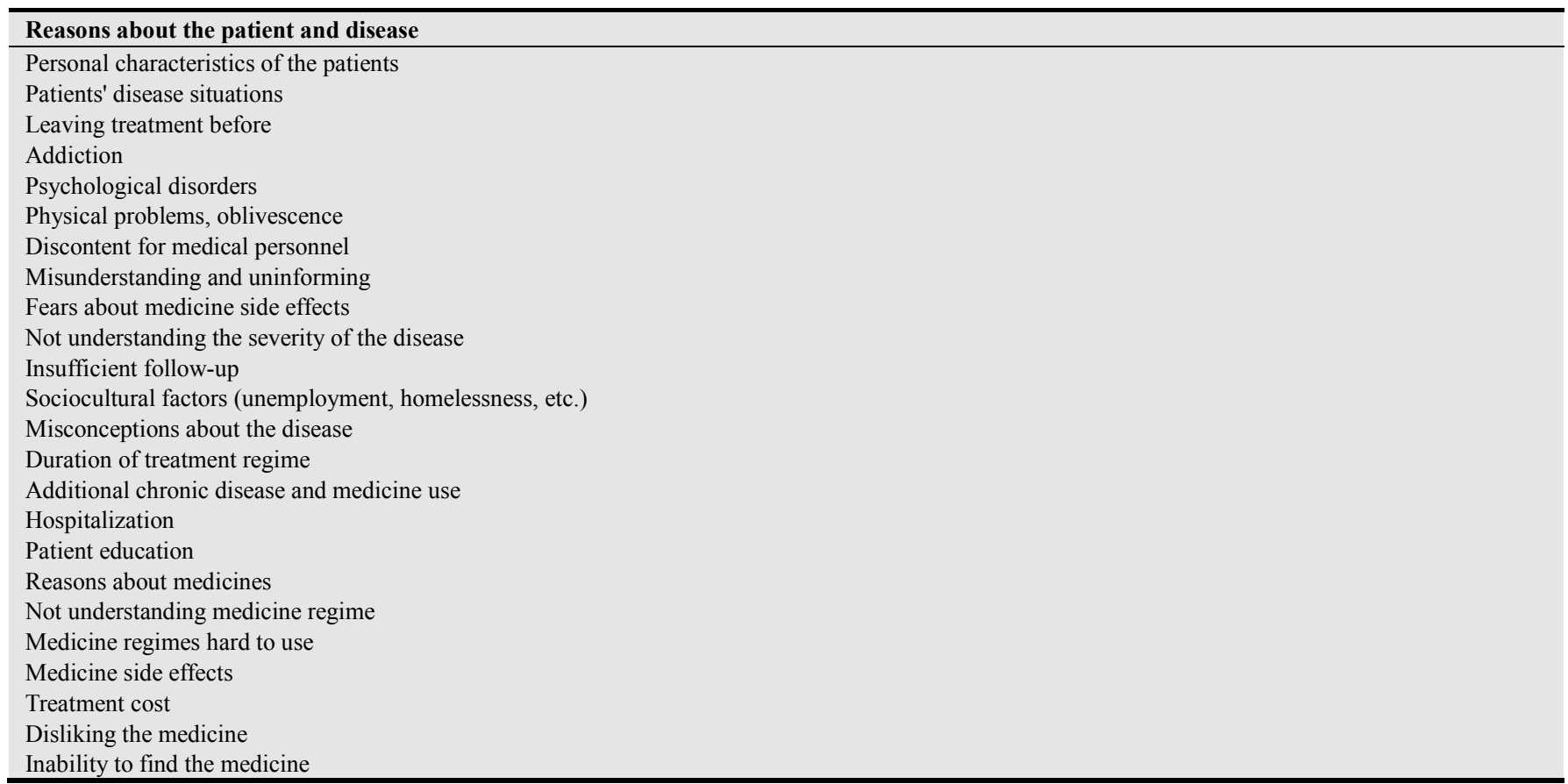

The most common treatment adherence problem observed is patients not applying to treatment methods or disregarding the disease unless dyspeptic complaints arise. The factors which make the patients most uncomfortable are dyspeptic complaints increasing at night and waking the patient up. Even when this is a common situation, patients try to relieve their complaints with food or irregular anti-acid medicine intake. Additional medicine use of patients also being important, as the number of medicines used increases, the patients care less about all the diseases and themselves. So patients want to decrease the number of medicines they use and first of all they stop using dyspepsia medicines they consider as the least necessary.

\section{Results and Recommendations}

It was observed that the kinds of anti-acid forms used for dyspepsia is not important for treatment adherence and the important fact was patient adherence characteristics. Especially in patients with alarm symptoms shown in Table 1, it was observed that sparing the required time for patient education on the importance of the disease and its treatment is the most important factor in treatment adherence.

Dyspepsia has a long treatment requiring sufficient time and dose. The aim in situations requiring long-term medicine use is to convince the patient for taking the medicines and 
coming for controls until the end of the treatment. Patient and health personnel have the most important role here. Many methods from patient-doctor cooperation, awarding the patient following the treatment and controls regularly can be tried (Table 3)(14).

Table 3. Methods increasing treatment adherence.

- Patient-doctor cooperation

- Decreasing special technical terms

- Decreasing cultural differences

- Problems in clinics or dispensaries

- Incentive and strengthening methods

- Treatment under direct observation

\section{References}

[1] Heading RC. Prevalance of upper gastrointestinal symptoms in the general population: a systematic review. Scand J Gastroenreology 1999; 34: 3-8.

[2] Talley NJ, Phillips SF. Non-ulcer dyspepsia: potential causes and pathophysiology. Ann Intern Med 1988; 108: 865-879.

[3] Talley NJ, Stanghellini V, Heading RC, et al. Functional gastroduodenal disorders. Gut 1999; 5: 37- 42.

[4] Karabulut S, Karabulut M, Akarsu C, Bozkurt MA, Bademler $\mathrm{S}$, Kocataş A, Basat S, Alış H. To investigate possible etiologic factors of organic and functional dyspepsia in Turkey: Medical Journal of Bakırköy 2015;11:17-23).

[5] Agreus L. The epidemiology of functional gastrointestinal disorders. Eur J Surg 1998; 583: 60-66.

[6] Knill-Jones RP. Geographical differences in the prevalence of dyspepsia. Scand J Gastroenterology 1991; 26: 17-24.

[7] Dağlı Ü, Kosar Y, Över H, ve ark. Kronik dispepside Helikobakter pilori ve semptom profili. Turk J Gastroenterology 1998; 1: 47-50.

[8] Pilichiewicz AN, Feltrin KL, Horowitz M, et al. Oral carbohydrate and fat differentially modulate symptoms, gut hormones and antral area in functional dyspepsia. Gastroenterology 2008; 134: A-435.
[9] Talley NJ, Vakil NB, Moayyedi P. American Gastroenterological Association technical review on the evaluation of dyspepsia. Gastroenterology 2005; 129: 17561780.

[10] Talley NJ, Vakil N, Delaney B, et al. Management issues in dyspepsia: current consensus and controversies. Scand J Gastroenterology 2004; 39: 913-918.

[11] Fisher RS, Parkman HP. Management of nonulcer dyspepsia. N Engl J Med 1998; 339: 1376-1381.

[12] Morisky DE, Malotte CK, Choi P et al. A patient education program to improve adherence rates with antituberculosis drug regimens. Health Educ Q 1990;17:253-67.

[13] Cuneo WD, Snider DE. Enhancing patient compliance with tuberculosis therapy. Clin Chest Med 1989;10: 375-80.

[14] Özşeker F, Akkaya E, Dilek İ, Damadoğlu E. Tüberküloz Hastalarının Tedaviye Uyumu (Hasta Kompliyans1). Solunum Hastalıkları 2004; 15: 109-115.

[15] Liam CK, Lim KH, Wong CM, Tang BG. Attitudes and knowledge of newly diagnosed tuberculosis patients regarding the disease and factors affecting treatment compliance. Int $\mathbf{J}$ Tuberc Lung Dis 1999;3:300-9.

[16] Pablos-Mendez A, Knirsch CA, Barr RG et al. Nonaderence in tuberculosis treatment: Predictors and consequences in New York City. Am J Med 1997;102:164-70.

[17] WHO Tuberculosis Programme. FrameWork For Effective Tuberculosis Kontrol. Geneva. Switzerland. WHO/TB/ 1994;94:179.

[18] O'Boyle SJ, Power JJ, Ibrahim MY, Watson JP. Factors effecting patients compliance with antituberculosis chemotherapy using the directly observed treatment, shortcourse strategy (DOTS). Int J Tuberc Lung Dis 2002; 6:30712.

[19] Spector SL,Levis CE. Worhshop 6: Compliance factors. J Allegy Clin Immunol 1986;78:529-33.

[20] Saito YA, Locke GR, Weaver AL, et al. Diet and functioanl gastrointestinal disorders. A population-based case-control study. Am J Gastroenterol 2005;100:2743-8. 